\title{
Influence of anti-TNF therapy on mortality in patients with rheumatoid arthritis-associated interstitial lung disease: results from the British Society for Rheumatology Biologics Register
}

\author{
W G Dixon, ${ }^{1} \mathrm{~K}$ L Hyrich, ${ }^{1} \mathrm{~K}$ D Watson, ${ }^{1}$ M Lunt, ${ }^{1}$ BSRBR Control Centre Consortium, ${ }^{2}$ \\ D P M Symmons ${ }^{1}$ on behalf of the British Society for Rheumatology Biologics \\ Register
}

\begin{abstract}
${ }^{1}$ Arthritis Research UK Epidemiology Unit, Manchester Academic Health Sciences Centre, University of Manchester, Manchester, UK ${ }^{2}$ British Society for Rheumatology Biologics Register, Manchester, UK
\end{abstract}

\section{Correspondence to} Professor Deborah Symmons, University of Manchester, Stopford Building, Oxford Road, Manchester M13 9PT, UK; deborah.symmons@manchester.ac.uk

Accepted 3 December 2009

\begin{abstract}
Background Anti-tumour necrosis factor (anti-TNF) therapy has been associated with reports of rapid severe progression of rheumatoid arthritis-associated interstitial lung disease (RA-ILD). However, reports also exist of favourable responses to anti-TNF therapy in patients with ILD. The aim of this study was to examine the influence of anti-TNF therapy on mortality in patients with pre-existing RA-ILD.

Methods Using data from the British Society for Rheumatology Biologics Register, a national prospective observational study, 367 patients with pre-existing RA-ILD were identified (299 treated with anti-TNF therapy and 68 treated with traditional disease-modifying antirheumatic drugs (DMARDs)).
\end{abstract}

Results 70/299 patients (23\%) in the anti-TNF cohort died after a median follow-up of 3.8 years compared with $14 / 68(21 \%)$ in the DMARD cohort after a median follow-up of 2.1 years. The mortality was 68 deaths/1000 person years (pyrs) (95\% Cl 53 to 86) in the anti-TNF cohort and $92 / 1000$ pyrs (95\% Cl 50 to 155$)$ in the DMARD cohort, generating an age- and sex-adjusted mortality rate ratio (aMRR) of 1.26 ( $95 \% \mathrm{Cl} 0.69$ to 2.31 ). After further adjustment for potential confounders, the aMRR fell to 0.81 (95\% Cl 0.38 to 1.73) for the anti-TNF cohort compared with the DMARD cohort. RA-ILD was the underlying cause of death in 15/70 (21\%) and 1/14 (7\%) patients in the anti-TNF and DMARD cohorts, respectively. Conclusion The mortality in patients with RA-ILD is not increased following treatment with anti-TNF therapy compared with traditional DMARDs. The proportion of deaths attributable to RA-ILD is higher in patients treated with anti-TNF therapy, although reporting bias may exist.

\section{INTRODUCTION}

Rheumatoid arthritis (RA) is associated with extra-articular manifestations in around $40 \%$ of patients. ${ }^{1} 2$ Respiratory manifestations are common and include airways, pleural and interstitial disorders. Rheumatoid arthritis-associated interstitial lung disease (RA-ILD) is a non-neoplastic disorder resulting from damage to the lung parenchyma by varying patterns of inflammation and fibrosis. ${ }^{3}$ Estimates of prevalence vary widely from $1 \%$ to $80 \%$, the broad range reflecting differences in disease definitions and populations studied. ${ }^{4}$

RA-ILD is associated with a significant mortality. Estimates of 2-year mortality in patients with prevalent disease are $>20 \% .{ }^{5}$ RA-ILD is the direct cause of death in $4 \%$ of unselected patients with RA, while featuring on the death certificate in $6 \%$. Following the introduction of anti-tumour necrosis factor (anti-TNF) therapies for patients with RA, there have been a number of case reports and case series documenting either a rapid progression of pre-existing RA-ILD or the development of newonset interstitial disease. Such reports exist for each of the three currently licensed anti-TNF therapies: infliximab (INF), etanercept (ETA) and adalimumab (ADA). ${ }^{8-14}$ Nineteen out of 20 of these cases of progressive RA-ILD occurred less than 3 months after starting anti-TNF therapy, providing a persuasive argument for causality despite the limitations of spontaneous pharmacovigilance. Eight of the 20 cases were fatal. These reports have led to the inclusion of ILD as an 'undesirable effect' in the Summary of Product Characteristics for each of the three drugs. However, in direct contrast, there are also reports of anti-TNF therapy stabilising or improving lung function in patients with RA-ILD. ${ }^{15-17}$ These paradoxical effects are, however, supported by animal models of both profibrotic and antifibrotic effects of TNF in the lung. ${ }^{18}$

The aim of this study was to examine the influence of anti-TNF therapy on all-cause and ILDspecific mortality in patients with pre-existing RA-ILD.

\section{METHODS \\ Patients}

The subjects for this analysis were participating in a large national prospective observational study, the British Society for Rheumatology Biologics Register (BSRBR). The methods of patient recruitment and follow-up have been described in detail elsewhere. ${ }^{19}$ Briefly, the study was established in 2001 to examine the long-term safety of biological drugs in patients with RA. Recruitment targets of 4000 patients with RA treated with each of the three anti-TNF drugs, as well as 4000 biologicnaive patients with active $R A$ receiving standard disease-modifying antirheumatic drug (DMARD) therapy, were set in the first years of the study. UK national guidelines recommend that anti-TNF drugs are reserved for patients with active RA (defined as a 28-joint count disease activity score (DAS28) >5.1) despite previous therapy with at 
least two DMARDs, one of which should be methotrexate, ${ }^{20}$ and that 'any clinician prescribing these medications must (with the patient's permission) undertake to register the patient with the BSRBR and forward information on dosage, outcome and toxicity on a six-monthly basis'. ${ }^{21}$ Recruitment targets for the ETA cohort were met in 2005, for the INF cohort in 2007 and for the ADA cohort in 2008. No accurate figures for anti-TNF penetration in the UK RA population exist, although estimates of around $7 \%$ have been suggested. ${ }^{22}$ Before recruitment targets were met, we estimated that $>80 \%$ of anti-TNF treated patients with RA in the UK were registered on the BSRBR.

\section{Anti-TNF cohort}

Analysis was restricted to patients registered with the BSRBR with a physician diagnosis of RA who were commencing an anti-TNF drug as their first biological drug. Patients registered more than 6 months after the start of biological therapy were excluded. All patients were registered before 30 June 2008.

\section{Comparison cohort}

The cohort of biologic-naive patients with active RA was recruited in parallel (see authorship list of the BSR Control Centre Consortium) and followed using identical methodology. ${ }^{19}$ These patients have a physician diagnosis of RA with active disease (guideline DAS28 $\geq 4.2$ ) despite current treatment with a traditional DMARD and are naive to biological agents. Comparison patients also had to be registered before 30 June 2008 .

\section{Baseline assessment}

Baseline information for both cohorts included demographic characteristics, disease duration, 28 swollen and 28 tender joint counts, erythrocyte sedimentation rate and/or C-reactive protein and patient global assessment which enables calculation of a DAS28 score. ${ }^{23}$ Rheumatoid factor (RhF) positivity was defined as the presence (ever) of a titre $\geq 1 / 40$. The presence of baseline RA-ILD was based on the response to the following question in the consultant baseline questionnaire: 'Has the patient ever had any of the following systemic features (of RA): pulmonary fibrosis?' Other extra-articular manifestations of rheumatoid arthritis (EARA) were defined as the presence (ever) of one or more of sicca syndrome, serosal involvement (pleuritis/pericarditis), eye involvement, systemic vasculitis or nailfold vasculitis. Details of all previous DMARD therapy and all current medications were obtained, as well as smoking history and comorbidity. Patients completed a Health Assessment Questionnaire (HAQ) adapted for British use. ${ }^{24}$

\section{Follow-up}

Data on changes in therapy, disease activity and the occurrence of adverse events were captured in three ways: 6-monthly rheumatologist questionnaire, 6-monthly patient diary and by 'flagging' with the UK Office for National Statistics (ONS) who provided information on mortality including cause of death coded according to the International Classification of Diseases 10 (ICD-10).

After 3 years of follow-up, consultant questionnaires were sent annually and patient diaries were no longer sent. Deaths occurring before 30 June 2008, notified from any source, were included in the all-cause mortality analyses. Data were collected until December 2008 to allow for a delay between the date of death and the notification of death being received by the BSRBR from the ONS. Analysis by cause of death was limited to those deaths where notification had been received from the ONS.
RA-ILD was identified from the death certificate using the ICD-10 codes J84.1 'Interstitial pulmonary diseases with fibrosis', J84.9 'Interstitial pulmonary disease, unspecified' and M05.1 'Rheumatoid lung'. RA-ILD deaths were categorised into recording of RA-ILD anywhere on the death certificate and RA-ILD as the underlying cause of death (a subset of the former).

\section{Statistical analysis}

Patients contributed person years (pyrs) of follow-up from their registration date (anti-TNF start date for the anti-TNF cohort) until the cut-off date (30 June 2008) or the date of death, whichever came sooner. Patients continued to contribute pyrs for the duration of follow-up, irrespective of drug discontinuation, switching between anti-TNF therapies (for the anti-TNF cohort) or the return of consultant questionnaires. Patients could switch from the DMARD cohort to the anti-TNF cohort. Such patients contributed pyrs of follow-up to the DMARD cohort up to the date an anti-TNF drug was started and subsequent follow-up to the anti-TNF cohort. Patients could not switch from the antiTNF to the DMARD cohort.

Mortalities are presented as the number of deaths/1000 pyrs with $95 \%$ CI. Mortality rate ratios (MRRs) were calculated using Cox regression, comparing the anti-TNF cohort with the DMARD cohort. Adjustment was made for age, gender and calendar year of recruitment. Multivariable regression was performed with additional confounders identified from an a priori list of possible confounders including smoking (current/former/ never), diabetes, chronic obstructive pulmonary disease (COPD)/ asthma, prior tuberculosis, disease severity (HAQ, DAS28 and disease duration as continuous variables), EARA, RhF positivity, number of prior DMARDs, baseline methotrexate use (yes/no) and baseline steroid use (yes/no). Analysis exploring potential confounders was done both by limiting analysis to patients with complete data and by imputing missing data to include all patients. True confounders were identified by sequentially including each confounder in the regression model, and including in the multiple variable regression those confounders that individually changed the estimation after adjustment by more than $10 \% .{ }^{25}$ All analyses were performed using Stata 9.2 (StataCorp, College Station, Texas, USA).

\section{RESULTS}

A total of 13883 patients were included in the analyses, 3464 in the DMARD cohort and 10649 patients had ever received an anti-TNF drug; 210 patients switched from the DMARD cohort to the anti-TNF cohort and contributed pyrs to both cohorts. In all, 2725 patients in the anti-TNF cohort were known to have been exposed to more than one anti-TNF drug during follow-up. The anti-TNF treated cohort had more severe disease than the DMARD cohort (table 1).

Sixty-eight patients in the DMARD cohort and 299 patients in the anti-TNF cohort had physician-reported RA-ILD at baseline. The RA-ILD cohorts were older and comprised proportionally more men than patients without RA-ILD (table 1). They also had slightly higher disease activity and longer disease duration. Patients with RA-ILD at baseline had more other EARA than patients without RA-ILD, as well as more COPD/ asthma. Higher proportions of patients with RA-ILD had ever smoked. Fewer patients with RA-ILD were using methotrexate at baseline. All subsequent analyses are limited to patients with baseline RA-ILD. Three patients with baseline RA-ILD contributed pyrs to both cohorts. 
Considering only patients with RA-ILD, the anti-TNF RA-ILD cohort was younger with more severe disease including more EARA than the DMARD RA-ILD cohort. COPD/asthma was balanced in the two cohorts, as was smoking status. The median pyrs of follow-up per patient was 2.1years for the DMARD RA-ILD cohort and 3.8years for the anti-TNF RA-ILD cohort (table 2). Fourteen of 68 (21\%) of the DMARD RA-ILD cohort died during this follow-up period compared with 70 of $299(23 \%)$ of the anti-TNF RA-ILD cohort. None of the three patients who contributed pyrs to both the DMARD and the anti-TNF RA-ILD cohorts died.

The all-cause mortality was 68 deaths $/ 1000$ pyrs $(95 \%$ CI 53 to 86) in the anti-TNF RA-ILD cohort compared with 92 deaths/1000 pyrs (95\% CI 50 to 155 ) in the DMARD RA-ILD cohort (table 2 and figure 1). After adjustment for age and gender, the adjusted mortality rate ratio (aMRR) was 1.26 (95\% CI 0.69 to 2.31) for the anti-TNF RA-ILD cohort compared with the DMARD RA-ILD cohort. However, after full adjustment for potential confounders, the aMRR fell to 0.81 (0.38 to 1.73). Of the potential confounders, age, gender, calendar year of entry, disease duration, $\mathrm{HAO}, \mathrm{DAS} 28$ score, COPD/asthma, baseline steroid use and baseline methotrexate use were included in the multivariate model. The only significant predictors of mortality were age (HR 2.28 (95\% CI 1.64 to 3.15) per decade) and DAS28 score (HR 1.43 (95\% CI 1.11 to 1.85 ) per unit increase).

RA-ILD was the underlying cause of death in $15 / 70$ patients (21\%) who died in the anti-TNF RA-ILD cohort compared with $1 / 14(7 \%)$ in the DMARD RA-ILD cohort (table 3$)$. The proportion of deaths where RA-ILD was recorded anywhere on the death certificate was also higher in the anti-TNF RA-ILD cohort

Table 1 Baseline characteristics

\begin{tabular}{|c|c|c|c|c|}
\hline & \multicolumn{2}{|l|}{ DMARD $(n=3464)$} & \multicolumn{2}{|l|}{ Anti-TNF ( $n=10649)$} \\
\hline & $\begin{array}{l}\text { No baseline } \\
\text { RA-ILD ( } n=3396)\end{array}$ & $\begin{array}{l}\text { Baseline } \\
\text { RA-ILD (n=68) }\end{array}$ & $\begin{array}{l}\text { No baseline } \\
\text { RA-ILD (n=10350) }\end{array}$ & $\begin{array}{l}\text { Baseline } \\
\text { RA-ILD ( } n=299)\end{array}$ \\
\hline Mean (SD) age (years) & $60(12)$ & $68(9)$ & $56(12)$ & $63(10)$ \\
\hline Females, n (\%) & $2462(73)$ & 60 & $7889(76)$ & 57 \\
\hline Mean (SD) DAS28 & $5.1(1.3)$ & $5.2(1.2)$ & $6.5(1.0)$ & $6.7(1.0)$ \\
\hline Mean (SD) HAO & $1.5(0.8)$ & $1.8(0.7)$ & $2.0(0.6)$ & $2.1(0.5)$ \\
\hline Median (IQR) disease duration (years) & $6(1-15)$ & $12(5-22)$ & $11(6-19)$ & $12(7-20)$ \\
\hline RhF positivity, n (\%) & $1953(58)$ & $50(74)$ & $6616(64)$ & $226(76)$ \\
\hline Baseline EARA, $\mathrm{n}(\%)$ & $602(18)$ & $26(38)$ & $2812(27)$ & $163(55)$ \\
\hline Baseline steroid use, $\mathrm{n}(\%)$ & 759 (22) & $37(54)$ & $4522(44)$ & $171(57)$ \\
\hline Diabetes, n (\%) & $219(7)$ & $10(15)$ & $592(6)$ & $17(6)$ \\
\hline COPD/asthma, n (\%) & $622(18)$ & $19(28)$ & $1352(13)$ & $73(25)$ \\
\hline \multicolumn{5}{|l|}{ Smoking, $\mathrm{n}(\%)$} \\
\hline Current & $796(23)$ & $16(24)$ & $2270(22)$ & $61(20)$ \\
\hline Former & $1338(39)$ & $36(53)$ & $3878(37)$ & $166(56)$ \\
\hline Never & $1245(37)$ & $16(24)$ & $4139(40)$ & $72(24)$ \\
\hline Median (IQR) number of prior DMARDs & $2(1-3)$ & $4(2-5)$ & $4(3-5)$ & $4(3-5)$ \\
\hline Baseline methotrexate use, $\mathrm{n}(\%)$ & $2097(64)$ & $20(30)$ & $5693(57)$ & $109(38)$ \\
\hline
\end{tabular}

Table 2 Mortality in DMARD and anti-TNF cohorts stratified by baseline RA-ILD

\begin{tabular}{|c|c|c|c|c|}
\hline & \multicolumn{2}{|l|}{ DMARD } & \multicolumn{2}{|l|}{ Anti-TNF } \\
\hline & No baseline RA-ILD & Baseline RA-ILD & No baseline RA-ILD & Baseline RA-ILD \\
\hline Patients (n) & 3396 & 68 & 10350 & 299 \\
\hline Total pyrs of follow-up & 8782 & 152 & 38423 & 1026 \\
\hline $\begin{array}{l}\text { Median (IQR) follow-up } \\
\text { per person (years) }\end{array}$ & $2.6(1.7-3.6)$ & $2.1(1.3-3.1)$ & $3.9(2.7-4.9)$ & $3.8(2.0-4.7)$ \\
\hline \multicolumn{5}{|l|}{ Deaths } \\
\hline All-cause (n) & 181 & 14 & 635 & 70 \\
\hline All-cause mortality/1000 pyrs & 21 (18 to 24$)$ & $92(50$ to 155$)$ & $17(15$ to 18$)$ & 68 (53 to 86$)$ \\
\hline RA-ILD as cause, $\mathrm{n}(\%)$ & $2(1)$ & $1(7)$ & $14(2)$ & $15(21)$ \\
\hline RA-ILD on cert, $n$ (\%) & $4(2)$ & $2(14)$ & $25(4)$ & $24(34)$ \\
\hline MRR (unadjusted (95\% CI)) & & Referent & & $0.74(0.42$ to 1.33$)$ \\
\hline $\begin{array}{l}\text { MRR (adjusted for age and } \\
\text { gender }(95 \% \mathrm{CI}) \text { ) }\end{array}$ & & Referent & & 1.26 (0.69 to 2.31$)$ \\
\hline $\begin{array}{l}\text { MRR (adjusted for age and gender } \\
\text { and calendar year }(95 \% \mathrm{CI}))\end{array}$ & & Referent & & 1.14 (0.58 to 2.26$)$ \\
\hline \multicolumn{5}{|l|}{ MRR (fully adjusted* $(95 \% \mathrm{CI})$ ) } \\
\hline $\begin{array}{l}\text { Using patients with complete } \\
\text { data sets }\end{array}$ & & Referent & & 0.80 (0.34 to 1.87$)$ \\
\hline Using imputed data & & Referent & & $0.81(0.38$ to 1.73$)$ \\
\hline
\end{tabular}




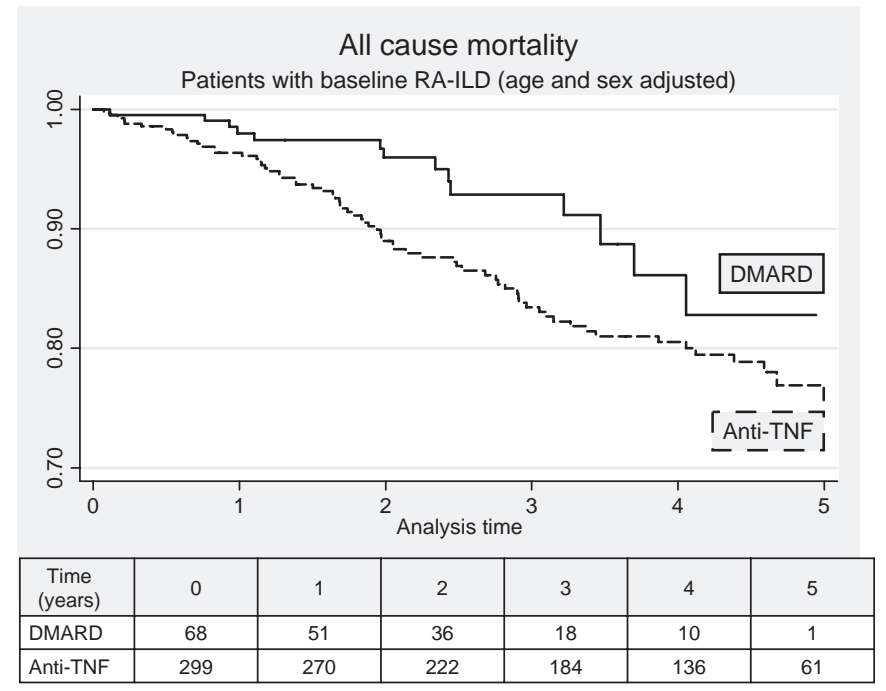

Figure 1 Influence of anti-TNF therapy on all-cause mortality in patients with pre-existing RA-ILD, adjusted for age and gender. Numbers in table represent the number of patients included in follow-up at annual time points. Anti-TNF, anti-tumour necrosis factor; DMARD, diseasemodifying antirheumatic drug; RA-ILD, rheumatoid arthritis-associated interstitial lung disease.

Table 3 Cause of death in patients with baseline RA-ILD

\begin{tabular}{lll}
\hline & $\begin{array}{l}\text { DMARD } \\
\text { cohort (n=14) }\end{array}$ & $\begin{array}{l}\text { Anti-TNF } \\
\text { cohort }(\mathbf{n}=\mathbf{7 0})^{*}\end{array}$ \\
\hline RA-ILD on death certificate & $1(7)$ & $15(22)$ \\
ILD as immediate cause of death & $2(14)$ & $24(35)$ \\
ILD present on death certificate & & \\
Underlying cause of death by ICD-10 chapter & - & $3(4)$ \\
$\quad$ Certain infectious and parasitic diseases & $5(36)$ & $9(13)$ \\
Neoplasms & - & $1(1)$ \\
Diseases of the blood and blood-forming organs & - & $1(1)$ \\
Endocrine, nutritional and metabolic diseases & - & $13(19)$ \\
Circulatory & $4(29)$ & $20(29)$ \\
Respiratory & $3(21)$ & $2(3)$ \\
Digestive & - & $17(24)$ \\
Musculoskeletal and connective tissue & $2(14)$ & $2(3)$ \\
Genitourinary & - & $1(1)$ \\
External causes & - & $1(1)$ \\
Missing & - &
\end{tabular}

Figures represent number (\%) of deaths.

${ }^{*}$ One missing cause of death in anti-TNF cohort. Percentages represent proportion of 69 patients with a reported cause of death.

DMARD, disease-modifying antirheumatic drug; ILD, interstitial lung disease; RA-ILD, rheumatoid arthritis-associated ILD; TNF, tumour necrosis factor.

than in the DMARD RA-ILD cohort (24/70 (34\%) vs 2/14 (14\%)). The age- and sex-adjusted MRR for deaths where ILD featured on the death certificate was 2.63 (95\% CI 0.60 to 11.45) for the anti-TNF RA-ILD cohort compared with the DMARD RA-ILD cohort. We also explored the frequency of RA-ILD-related deaths in patients without baseline RA-ILD. The proportion of deaths for which RA-ILD was the underlying cause was significantly lower in patients who did not have pre-existing RA-ILD (14/635 $(2 \%)$ deaths in the anti-TNF cohort vs $2 / 181$ deaths $(1 \%)$ in the DMARD cohort). Similarly, the proportions of deaths where RA-ILD was recorded anywhere on the certificate were much lower in patients without baseline RA-ILD (25/638 deaths (4\%) in the anti-TNF cohort vs $4 / 181$ deaths $(2 \%)$ in the DMARD cohort). When comparing mortalities in patients with RA-ILD compared with no baseline RA-ILD, baseline RA-ILD was a strong predictor of all-cause mortality in both the anti-TNF and DMARD cohorts (age- and sex-adjusted MRR 2.85 (95\% CI 2.22 to 3.66 ) and 2.69 (95\% CI 1.55 to 4.67 ), respectively).

\section{DISCUSSION}

We have shown that the mortality in patients with RA-ILD is not increased following treatment with anti-TNF therapy compared to treatment with traditional DMARDs. However, the proportion of deaths attributable to RA-ILD is higher in patients treated with anti-TNF therapy.

There are a number of methodological issues to consider when interpreting these data. The first important issue is what the reporting of baseline RA-ILD constitutes, and whether this may have differed between the treatment arms. Patients with baseline RA-ILD were identified in response to the question on the consultant baseline questionnaire: 'Has the patient ever had any of the following systemic features (of RA): pulmonary fibrosis?'. Patients may have been misclassified in either direction. It is possible that patients reported to have baseline RA-ILD did not have the disease. Such misclassification was unlikely to have been imbalanced in the two treatment arms or to introduce bias. The opposite misclassification is more likely: where patients with true RA-ILD at baseline were not reported to the register. Most rheumatologists do not systematically screen for ILD and they may have varying thresholds for initiating investigations. Severe ILD is more likely to be diagnosed than mild ILD.

Anti-TNF safety signals in patients with RA-ILD have been published since 2004. ${ }^{26}$ Consequently, clinicians may have been less inclined to prescribe anti-TNF therapy to patients with severe RA-ILD. As increasing RA-ILD severity is probably associated with increased mortality, such a selection bias would relatively increase the mortality in the DMARD cohort and lead to a reduction in our estimates of MRR. We should therefore conclude from our results that the way in which UK rheumatologists select patients with pre-existing RA-ILD to receive antiTNF therapy is not leading to an increase in all-cause mortality, rather than concluding that anti-TNF therapy does not increase the mortality in unselected patients with RA-ILD.

Despite the original cohort size of nearly 14000 patients, there were only 364 patients with baseline RA-ILD, of whom $84(23 \%)$ died. The small population size has implications for the precision of the estimated relative risk of death attributable to anti-TNF therapy, and is particularly sensitive to the number of deaths in the DMARD RA-ILD cohort, given its smaller size. The aMRR of 0.81 (95\% CI 0.38 to 1.73) has wide CIs following adjustment for multiple potential confounders. Although the number of deaths was relatively small, the final inclusion of eight confounders did not contravene guidance that there should be more than 10 events per variable in the model. ${ }^{27}$ The precision of the estimate could be narrowed with a larger population size. However, this result represents the outcome of a national study conducted over 7 years, and we must accept it as the best available estimate of risk with respect to this important clinical question at this stage.

We were able to measure and adjust for many potential confounders. These included smoking, other EARA and RhF positivity, all of which were more common in patients with baseline RA-ILD. While stepwise adjustment led to moderate changes in the aMRR point estimate, fluctuation was always around unity, reinforcing the absence of an increased risk. As with most observational studies, there may be remaining unmeasured or residual confounding. As mentioned above, RA-ILD severity may have 
been higher in the DMARD cohort. Unfortunately, despite our efforts to do so, it was not possible to collect robust high-quality data retrospectively about baseline RA-ILD severity.

The proportion of deaths where RA-ILD was recorded on the death certificate was higher in the anti-TNF-treated RA-ILD cohort. The proposed selection bias favouring less severe RA-ILD in the anti-TNF cohort would not explain this finding. Alternative explanations include anti-TNF therapy truly increasing the proportion of deaths attributable to RA-ILD, or clinicians being more inclined to report RA-ILD on the death certificates of patients treated with anti-TNF therapy. Given the existing safety concerns, this latter possibility is plausible.

Less than $3 \%$ of patients in this study were reported to have baseline RA-ILD, despite the BSRBR population including only patients with severe active RA. Although estimates of the prevalence of RA-ILD in the literature vary according to the definition of RA-ILD, the cohort under study and the investigation technique, values range from $1 \%$ to $80 \% .{ }^{128-30}$ Our low prevalence of $2.6 \%$ would support the suggestion that physicians are identifying only a proportion of the patients who have RA-ILD. As a benchmark of RA-ILD mortality, a UK inception cohort of patients with RA treated in the prebiological era reported $4 \%$ of deaths due to RA-ILD, ${ }^{7}$ which is comparable to the $3 \%$ of deaths attributable to RA-ILD in the BSRBR DMARD cohort. Our finding of a nearly threefold higher mortality in patients with RA-ILD than in patients with no RA-ILD replicates recent results from the Mayo Clinic. ${ }^{31}$

An observational study by Wolfe et al has previously attempted to investigate the association between anti-TNF therapy and the risk of hospitalisation for RA-ILD. ${ }^{32}$ Although they reported a univariate association between prior anti-TNF use and hospitalisation for RA-ILD, the authors acknowledge this probably represents confounding by indication, concluding that they were unable to make any inference about causality.

Despite initial concerns about the safety of anti-TNF therapy in patients with RA-ILD, our study has not found an increased rate of mortality. This is reassuring, and suggests that UK clinicians are currently making appropriate decisions about which patients with RA-ILD to treat with anti-TNF. However, it should not be assumed that it is safe to prescribe anti-TNF therapy to unselected patients with RA-ILD. Our analysis does not enable us to advise on whether patients should be screened prior to treatment, how patients should be selected for treatment, or how patients should be monitored once treatment is commenced.

BSRBR Control Centre Consortium Antrim Area Hospital, Antrim (Dr Nicola Maiden); Cannock Chase Hospital, Cannock Chase (Dr Tom Price); Christchurch Hospital, Christchurch (Dr Neil Hopkinson); Derbyshire Royal Infirmary, Derby (Dr Sheila O'Reilly): Dewsbury and District Hospital, Dewsbury (Dr Lesley Hordon): Freeman Hospital, Newcastle-upon-Tyne (Dr lan Griffiths); Gartnavel General Hospital, Glasgow (Dr Duncan Porter); Glasgow Royal Infirmary, Glasgow (Professor Hilary Capell); Haywood Hospital, Stoke-on-Trent (Dr Andy Hassell); Hope Hospital, Salford (Dr Romela Benitha); King's College Hospital, London (Dr Ernest Choy); Kings Mill Centre, Sutton-In Ashfield (Dr David Walsh); Leeds General Infirmary, Leeds (Professor Paul Emery); Macclesfield District General Hospital, Macclesfield (Dr Susan Knight); Manchester Royal Infirmary, Manchester (Dr lan Bruce); Musgrave Park Hospital, Belfast (Dr Allister Taggart); Norfolk and Norwich University Hospital, Norwich (Professor David Scott); Poole General Hospital, Poole (Professor Paul Thompson); Queen Alexandra Hospital, Portsmouth (Dr Fiona McCrae); Royal Glamorgan Hospital, Glamorgan (Dr Rhian Goodfellow); Russells Hall Hospital, Dudley (Professor George Kitas); Selly Oak Hospital, Selly Oak (Dr Ronald Jubb); St Helens Hospital, St Helens (Dr Rikki Abernethy); Weston General Hospital, Weston-super-Mare (Dr Shane Clarke); Withington Hospital, Manchester (Dr Paul Sanders); Withybush General Hospital, Haverfordwest (Dr Amanda Coulson).

Acknowledgements The authors acknowledge the enthusiastic collaboration of all consultant rheumatologists and their specialist nurses in the UK in providing the data. In addition, we acknowledge the support from Dr lan Griffiths (Past) and Professor David Isenberg (Current), Chairs of the BSRBR Management Committee,
Professor Gabriel Panayi, Professor David GI Scott, Dr Andrew Bamii and Dr Deborah Bax, Presidents of the BSR during the period of data collection, for their active role in enabling the Register to undertake its tasks and to Samantha Peters (CEO of the BSR) Mervyn Hogg, Nia Taylor and members of the BSRBR Scientific Steering Committee. We also acknowledge the seminal role of the BSR Clinical Affairs Committee for establishing national biologic guidelines and recommendations for such a Register. Finally we would like to acknowledge the substantial contribution of Andy Tracey, Katie McGrother and ML in database design and manipulation and Professor Alan Silman in his prior role as a principal investigator of the BSRBR.

Competing interests None.

Ethics approval Ethical approval for this study was obtained in December 2000 from the Multicentre Research Ethics Committee (MREC) for the Northwest of England.

Provenance and peer review Not commissioned; externally peer reviewed.

Contributors WGD, study design, data analysis, interpretation, writing; KLH, study design, data management, interpretation, writing; KDW, study design, data management; ML, study design, data analysis; DPMS, study design, data management, interpretation, writing

The British Society for Rheumatology (BSR) commissioned the Biologics Register (BSRBR) as a UK-wide national project to investigate the safety of biologic agents in routine medical practice. DPMS and KLH are principal investigators on the BSRBR. BSR receives restricted income from UK pharmaceutical companies, presently Abbott Laboratories, Amgen, Schering Plough and Wyeth Pharmaceuticals. This income finances a wholly separate contract between the BSR and the University of Manchester who provide and run the BSRBR data collection, management and analysis services. The principal investigators and their team have full academic freedom and are able to work independently of pharmaceutical industry influence. All decisions concerning analyses, interpretation and publication are made autonomously of any industrial contribution. Members of the Manchester team, BSR trustees, committee members and staff complete an annual declaration in relation to conflicts of interest.

\section{REFERENCES}

1. Turesson C, O'Fallon WM, Crowson CS, et al. Extra-articular disease manifestations in rheumatoid arthritis: incidence trends and risk factors over 46 years. Ann Rheum Dis 2003;62:722-7.

2. Carmona L, González-Alvaro I, Balsa A, et al. Rheumatoid arthritis in Spain: occurrence of extra-articular manifestations and estimates of disease severity. Ann Rheum Dis 2003;62:897-900.

3. ATS/ERS Consensus Committee. American Thoracic Society/European Respiratory Society International Multidisciplinary Consensus Classification of the Idiopathic Interstitial Pneumonias. This joint statement of the American Thoracic Society (ATS), and the European Respiratory Society (ERS) was adopted by the ATS board of directors, June 2001 and by the ERS Executive Committee, June 2001. Am J Respir Crit Care Med 2002;165:277-304.

4. Kim DS. Interstitial lung disease in rheumatoid arthritis: recent advances. Curr Opin Pulm Med 2006;12:346-53

5. Dawson JK, Fewins HE, Desmond J, et al. Predictors of progression of HRCT diagnosed fibrosing alveolitis in patients with rheumatoid arthritis. Ann Rheum Dis 2002;61:517-21.

6. Akira M, Sakatani M, Hara H. Thin-section CT findings in rheumatoid arthritisassociated lung disease: CT patterns and their courses. J Comput Assist Tomogr 1999;23:941-8.

7. Young A, Koduri G, Batley M, et al. Mortality in rheumatoid arthritis. Increased in the early course of disease, in ischaemic heart disease and in pulmonary fibrosis. Rheumatology (Oxford) 2007;46:350-7.

8. Ostör AJ, Chilvers ER, Somerville MF, et al. Pulmonary complications of infliximab therapy in patients with rheumatoid arthritis. J Rheumatol 2006;33:622-8.

9. Kramer N, Chuzhin Y, Kaufman LD, et al. Methotrexate pneumonitis after initiation of infliximab therapy for rheumatoid arthritis. Arthritis Rheum 2002;47:670-1.

10. Lindsay K, Melsom R, Jacob BK, et al. Acute progression of interstitial lung disease: a complication of etanercept particularly in the presence of rheumatoid lung and methotrexate treatment. Rheumatology (Oxford) 2006;45:1048-9.

11. Quintos-Macasa AM, Quinet R. Enbrel-induced interstitial lung disease. South Med J 2006;99:783-4.

12. Hagiwara K, Sato T, Takagi-Kobayashi S, et al. Acute exacerbation of preexisting interstitial lung disease after administration of etanercept for rheumatoid arthritis. J Rheumatol 2007;34:1151-4.

13. Huggett MT, Armstrong R. Adalimumab-associated pulmonary fibrosis Rheumatology (Oxford) 2006;45:1312-13.

14. Schoe A, van der Laan-Baalbergen NE, Huizinga TW, et al. Pulmonary fibrosis in a patient with rheumatoid arthritis treated with adalimumab. Arthritis Rheum 2006;55:157-9.

15. Vassallo R, Matteson E, Thomas CF Jr. Clinical response of rheumatoid arthritisassociated pulmonary fibrosis to tumor necrosis factor-alpha inhibition. Chest 2002;122:1093-6. 
16. Dellapira PF, Fry TA, Willoughby J, et al. The treatment of interstitial lung disease associated with rheumatoid arthritis with Infliximab. Chest 2003;124:69S.

17. Antoniou KM, Mamoulaki M, Malagari K, et al. Infliximab therapy in pulmonary fibrosis associated with collagen vascular disease. Clin Exp Rheumatol 2007;25:23-8.

18. Distler JH, Schett G, Gay S, et al. The controversial role of tumor necrosis factor alpha in fibrotic diseases. Arthritis Rheum 2008:58:2228-35.

19. Watson K, Symmons D, Griffiths I, et al. The British Society for Rheumatology biologics register. Ann Rheum Dis 2005;64:iv42-3.

20. Ledingham J, Deighton C. Update on the British Society for Rheumatology guidelines for prescribing TNFalpha blockers in adults with rheumatoid arthritis (update of previous guidelines of April 2001). Rheumatology (Oxford) 2005;44:157-63.

21. National Institute for Health and Clinical Excellence. Guidance on the use of etanercept and infliximab for the treatment of rheumatoid arthritis. http://guidance.nice. org.uk/TA36/Guidance/pdf/English (accessed 25 Mar 2010).

22. Jönsson B, Kobelt G, Smolen J. The burden of rheumatoid arthritis and access to treatment: uptake of new therapies. Eur J Health Econ 2008;8(Suppl 2):S61-86.

23. Prevoo ML, van't Hof MA, Kuper HH, et al. Modified disease activity scores that include twenty-eight-joint counts. Development and validation in a prospective longitudinal study of patients with rheumatoid arthritis. Arthritis Rheum 1995;38:44-8.
24. Kirwan JR, Reeback JS. Stanford Health Assessment Questionnaire modified to assess disability in British patients with rheumatoid arthritis. Br J Rheumatol 1986;25:206-9.

25. Maldonado G, Greenland S. Simulation study of confounder-selection strategies. Am J Epidemiol 1993;138:923-36.

26. Ostor AJ, Crisp AJ, Somerville MF, et al. Fatal exacerbation of rheumatoid arthritis associated fibrosing alveolitis in patients given infliximab. BMJ 2004;329:1266.

27. Peduzzi P, Concato J, Feinstein AR, et al. Importance of events per independent variable in proportional hazards regression analysis. II. Accuracy and precision of regression estimates. J Clin Epidemiol 1995;48:1503-10.

28. Gabbay E, Tarala R, Will R, et al. Interstitial lung disease in recent onset rheumatoid arthritis. Am J Respir Crit Care Med 1997;156:528-35.

29. Wallaert B, Dugas M, Dansin E, et al. Subclinical alveolitis in immunological systemic disorders. Transition between health and disease? Eur Respir $\mathrm{J}$ 1990;3:1206-16.

30. Saag KG, Kolluri S, Koehnke RK, et al. Rheumatoid arthritis lung disease. Determinants of radiographic and physiologic abnormalities. Arthritis Rheum 1996;39:1711-19.

31. Nannini C, Ryu JH, Crowson CS, et al. Interstitial lung disease in rheumatoid arthritis: a population-based study. Arthritis Rheum 2008;58:S268.

32. Wolfe F, Caplan L, Michaud K. Rheumatoid arthritis treatment and the risk of severe interstitial lung disease. Scand J Rheumatol 2007;36:172-8. 


\section{Corrections}

The department of one of the authors who co-authored all of the below papers has found that the affiliations were not correct. The correct affiliations for Professor P Emery, for all of the below articles, are: ${ }^{1}$ Section of Musculoskeletal Disease, Leeds Institute of Molecular Medicine, University of Leeds; ${ }^{2}$ NIHR Leeds Musculoskeletal Biomedical Research Unit, Leeds Teaching Hospitals Trust, Leeds, UK.

1. Keystone E, Emery P, Peterfy CG, et al. Rituximab inhibits structural joint damage in patients with rheumatoid arthritis with an inadequate response to tumour necrosis factor inhibitor therapies. Ann Rheum Dis 2009;68:216-21.

2. Doward LC, McKenna SP, Whalley D, et al. The development of the L-OoL: a quality-of-life instrument specific to systemic lupus erythematosus. Ann Rheum Dis 2009;68:196-200.

3. Potter C, Hyrich KL, Tracey A, et al. Association of rheumatoid factor and anticyclic citrullinated peptide positivity, but not carriage of shared epitope or PTPN22 susceptibility variants, with anti-TNF response in RA. Ann Rheum Dis 2009;68:69-74.

4. Smolen JS, Han C, van der Heijde DM, et al.; Active-Controlled Study of Patients Receiving Infliximab for the Treatment of Rheumatoid Arthritis of Early Onset (ASPIRE) Study Group. Radiographic changes in rheumatoid arthritis patients attaining different disease activity states with methotrexate monotherapy and infliximab plus methotrexate: the impacts of remission and tumour necrosis factor blockade. Ann Rheum Dis 2009;68:823-7.

5. Buch MH, Boyle DL, Rosengren S, et al. Mode of action of abatacept in rheumatoid arthritis patients having failed tumour necrosis factor blockade: a histological, gene expression and dynamic magnetic resonance imaging pilot study. Ann Rheum Dis 2009;68:1220-7.

6. Emery P, Van Vollenhoven R, Ostergaard M, et al. Guidelines for initiation of antitumour necrosis factor therapy in rheumatoid arthritis: similarities and differences across Europe. Ann Rheum Dis 2009;68:456-9.

7. Bejarano V, Conaghan PG, Proudman SM, et al. Long-term efficacy and toxicity of ciclosporin A in combination with methotrexate in poor prognosis rheumatoid arthritis Ann Rheum Dis 2009;68:761-3.

8. Rudwaleit M, Landewé R, van der Heijde D, et al. The development of Assessment of SpondyloArthritis international Society classification criteria for axial spondyloarthritis (part I): classification of paper patients by expert opinion including uncertainty appraisal. Ann Rheum Dis 2009;68:770-6.

9. Bennett AN, Marzo-Ortega H, Emery P, et al.; Leeds Spondyloarthropathy Group. Diagnosing axial spondyloarthropathy. The new Assessment in SpondyloArthritis international Society criteria: MRI entering centre stage. Ann Rheum Dis 2009;68:765-7.

10. Marzo-Ortega H, McGonagle D, O'Connor P, et al. Baseline and 1-year magnetic resonance imaging of the sacroiliac joint and lumbar spine in very early inflammatory back pain. Relationship between symptoms, HLA-B27 and disease extent and persistence. Ann Rheum Dis 2009;68:1721-7.

11. Gilworth G, Emery P, Gossec L, et al. Adaptation and cross-cultural validation of the rheumatoid arthritis work instability scale (RA-WIS). Ann Rheum Dis 2009;68:1686-90.

12. Gilworth G, Emery P, Gossec L, et al. Adaptation and cross-cultural validation of the RA-WIS (Work Instability Scale). Ann Rheum Dis 2009;68:1686-90.

13. Jarrett SJ, Sivera F, Cawkwell LS, et al. MRI and clinical findings in patients with ankylosing spondylitis eligible for anti-tumour necrosis factor therapy after a short course of etoricoxib. Ann Rheum Dis 2009;68:1466-9.

14. Haugeberg G, Conaghan PG, Quinn $\mathrm{M}$, et al. Bone loss in patients with active early rheumatoid arthritis: infliximab and methotrexate compared with methotrexate treatment alone. Explorative analysis from a 12-month randomised, double-blind, placebo-controlled study. Ann Rheum Dis 2009;68:1898-901.

15. Genovese MC, Breedveld FC, Emery P, et al. Safety of biological therapies following rituximab treatment in rheumatoid arthritis patients. Ann Rheum Dis 2009;68:1894-7

16. Kekow J, Moots RJ, Emery P, et al. Patient-reported outcomes improve with etanercept plus methotrexate in active early rheumatoid arthritis and the improvement is strongly associated with remission: the COMET trial. Ann Rheum Dis 2010;69:222-5

17. Furst DE, Keystone EC, Fleischmann R, et al. Updated consensus statement on biological agents for the treatment of rheumatic diseases, 2009. Ann Rheum Dis 2010;69(Suppl 1):i2-29.

18. Freeston JE, Wakefield RJ, Conaghan PG, et al. A diagnostic algorithm for persistence of very early inflammatory arthritis: the utility of power Doppler ultrasound when added to conventional assessment tools. Ann Rheum Dis 2010;69:417-9.

19. Jones $\mathbf{E}$, Churchman SM, English A, et al. Mesenchymal stem cells in rheumatoid synovium: enumeration and functional assessment in relation to synovial inflammation level. Ann Rheum Dis 2010;69:450-7.

20. Alten RE, Zerbini C, Jeka S, et al. Efficacy and safety of pamapimod in patients with active rheumatoid arthritis receiving stable methotrexate therapy. Ann Rheum Dis 2010;69:364-7.
21. Machold KP, Landewé R, Smolen JS, et al. The Stop Arthritis Very Early (SAVE) trial, an international multicentre, randomised, double-blind, placebo-controlled trial on glucocorticoids in very early arthritis. Ann Rheum Dis 2010;69:495-502.

22. Schoels M, Knevel R, Aletaha D, et al. Evidence for treating rheumatoid arthritis to target: results of a systematic literature search. Ann Rheum Dis 2010;69:638-43.

23. Smolen JS, Aletaha D, Bijlsma JW, et al.; T2T Expert Committee. Treating rheumatoid arthritis to target: recommendations of an international task force. Ann Rheum Dis 2010;69:631-7.

24. Burr ML, Naseem H, Hinks A, et al.; BIRAC Consortium; YEAR Consortium. PADI4 genotype is not associated with rheumatoid arthritis in a large UK Caucasian population. Ann Rheum Dis 2010;69:666-70.

25. Emery $\mathbf{P}$, Durez P, Dougados $\mathrm{M}$, et al. Impact of T-cell costimulation modulation in patients with undifferentiated inflammatory arthritis or very early rheumatoid arthritis: a clinical and imaging study of abatacept (the ADJUST trial). Ann Rheum Dis 2010;69:510-16.

26. Bennett AN, Rehman A, Hensor EM, et al. The fatty Romanus lesion: a noninflammatory spinal MRI lesion specific for axial spondyloarthropathy. Ann Rheum Dis 2010;69:891-4.

27. Nam JL, Winthrop KL, van Vollenhoven RF, et al. Current evidence for the management of rheumatoid arthritis with biological disease-modifying antirheumatic drugs: a systematic literature review informing the EULAR recommendations for the management of RA. Ann Rheum Dis 2010;69:976-86.

28. Smolen JS, Landewé R, Breedveld FC, et al. EULAR recommendations for the management of rheumatoid arthritis with synthetic and biological disease-modifying antirheumatic drugs. Ann Rheum Dis 2010;69:964-75.

29. Tan RJ, Gibbons LJ, Potter C, et al.; BRAGGSS. Investigation of rheumatoid arthritis susceptibility genes identifies association of AFF3 and CD226 variants with response to anti-tumour necrosis factor treatment. Ann Rheum Dis 2010;69:1029-35.

30. Robinson JI, Barrett JH, Taylor JC, et al.; YEAR Consortium; BRAGGSS. Dissection of the FCGR3A association with RA: increased association in men and with autoantibody positive disease. Ann Rheum Dis 2010;69:1054-7.

31. Cohen SB, Keystone E, Genovese MC, et al. Continued inhibition of structural damage over 2 years in patients with rheumatoid arthritis treated with rituximab in combination with methotrexate. Ann Rheum Dis 2010;69:1158-61.

32. Haugeberg G, Bennett AN, McGonagle D, et al. Bone loss in very early inflammatory back pain in undifferentiated spondyloarthropathy: a 1-year observational study. Ann Rheum Dis 2010;69:1364-6.

33. Schoels M, Aletaha D, Smolen JS, et al. Follow-up standards and treatment targets in rheumatoid arthritis: results of a questionnaire at the EULAR 2008. Ann Rheum Dis 2010;69:575-8

34. Eyre S, Flynn E, Martin P, et al. No evidence for association of the KLF12 gene with rheumatoid arthritis in a large UK cohort. Ann Rheum Dis 2010;69:1407-8.

35. Eyre S, Hinks A, Flynn E, et al. Confirmation of association of the REL locus with rheumatoid arthritis susceptibility in the UK population. Ann Rheum Dis 2010;69:1572-3

36. Orozco G, Eyre S, Hinks A, et al.; Wellcome Trust Case Control consortium YEAR Consortium. Association of CD40 with rheumatoid arthritis confirmed in a large UK case-control study. Ann Rheum Dis 2010;69:813-16.

37. Emery $\mathbf{P}$, Durez P, Dougados $M$, et al. Impact of T-cell costimulation modulation in patients with undifferentiated inflammatory arthritis or very early rheumatoid arthritis: a clinical and imaging study of abatacept (the ADJUST trial). Ann Rheum Dis 2010;69:510-16

38. Saleem B, Keen $\mathrm{H}$, Goeb V, et al. Patients with RA in remission on TNF blockers: when and in whom can TNF blocker therapy be stopped? Ann Rheum Dis 2010;69:1636-42.

39. Barkham N, Coates LC, Keen H, et al. Double-blind placebo-controlled trial of etanercept in the prevention of work disability in ankylosing spondylitis. Ann Rheum Dis 2010;69:1926-8.

40. Emery P, Deodhar A, Rigby WF, et al. Efficacy and safety of different doses and retreatment of rituximab: a randomised, placebo-controlled trial in patients who are biological naive with active rheumatoid arthritis and an inadequate response to methotrexate (Study Evaluating Rituximab's Efficacy in MTX iNadequate rEsponders (SERENE)). Ann Rheum Dis 2010;69:1629-35.

41. Dixon WG, Hyrich KL, Watson KD, et al.; BSRBR Control Centre Consortium; British Society for Rheumatology Biologics Register. Influence of anti-TNF therapy on mortality in patients with rheumatoid arthritis-associated interstitial lung disease: results from the British Society for Rheumatology Biologics Register. Ann Rheum Dis 2010;69:1086-91. 